\title{
Google Earth Engine Based Three Decadal Landsat Imagery Analysis for Mapping of Mangrove Forests and Its Surroundings in the Trat Province of Thailand
}

\author{
Uday Pimple1,2,3*, Dario Simonetti ${ }^{4}$, Asamaporn Sitthi'5, Sukan Pungkul6, Kumron Leadprathom ${ }^{6}$, \\ Henry Skupek ${ }^{7}$, Jaturong Som-ard ${ }^{8}$, Valery Gond ${ }^{3}$, Sirintornthep Towprayoon ${ }^{1}$

\begin{abstract}
${ }^{1}$ The Joint Graduate School of Energy and Environment (JGSEE) and Centre of Excellence on Energy Technology and Environment, King Mongkut's University of Technology Thonburi, Bangkok, Thailand ${ }^{2}$ Institutagronomique, vétérinaire et forestier de France (Agreenium), AgroParisTech, Paris, France ${ }^{3}$ CIRAD, UPR Forests and Societies (F\&S), Campus International de Baillarguet, Montpellier, France ${ }^{4}$ European Commission, Joint Research Centre, Directorate D-Sustainable Resources-Bio-Economy Unit, Ispra (VA), Italy ${ }^{5}$ Department of Geography, Faculty of Social Sciences, Srinakharinwirot University, Bangkok, Thailand ${ }^{6}$ Royal Forest Department, 61 Phaholyothin Road, Chatuchak, Bangkok, Thailand

${ }^{7}$ Department of Biotechnology, Faculty of Science and Technology, Suan Sunandha Rajabhat University, Bangkok, Thailand ${ }^{8}$ Department of Geography, Faculty of Humanities and Social Sciences, Mahasarakham University, MahaSarakham Province, Thailand

Email: *upimple@gmail.com, dario.simonetti@ec.europa.eu, cherryhihi@gmail.com,mr.sukan@gmail.com, kumron57@gmail.com, hskupek@gmail.com, Jaturong.somard@gmail.com,valery.gond@cirad.fr, sirin@jgsee.kmutt.ac.th
\end{abstract}

How to cite this paper: Pimple, U., Simonetti, D., Sitthi, A., Pungkul, S., Leadprathom, K., Skupek, H., Som-ard, J., Gond, V. and Towprayoon, S. (2018) Google Earth Engine Based Three Decadal Landsat Imagery Analysis for Mapping of Mangrove Forests and Its Surroundings in the Trat Province of Thailand. Journal of Computer and Communications, 6, 247-264. https://doi.org/10.4236/jcc.2018.61025

Received: December 8, 2017 Accepted: December 26, 2017 Published: December 29, 2017

\begin{abstract}
Monitoring and understanding the changes in mangrove ecosystems and their surroundings are required to determine how mangrove ecosystems are constantly changing while influenced by anthropogenic, and natural drivers. Consistency in high spatial resolution $(30 \mathrm{~m})$ satellite and high performance computing facilities are limiting factors to the process, with storage and analysis requirements. With this, we present the Google Earth Engine (GEE) based approach for long term mapping of mangrove forests and their surroundings. In this study, we used a GEE based approach: 1) to create atmospheric contamination free data from 1987-2017 from different Landsat satellite imagery; and 2) evaluating the random forest classifier and post classification change detection method. The obtained overall accuracy for the years 1987 and 2017 was determined to be 0.87 and 0.96 , followed by a Kappa coefficient 0.80 and 0.94 . The change detection results revealed a significant decrease in the agricultural area, while there was an increase in mangrove forest, shrimp/fish farm, and bareland area. The results suggest that interconversion of land use and land cover is affecting the landscape dynamics within the study area.
\end{abstract}




\section{Keywords}

Google Earth Engine, Landsat, Random Forest, Mangrove Forest, Land Use Land Cover Change

\section{Introduction}

Mangrove forests are located throughout the tropical and sub-tropical regions of the world, and are claimed to be one of the most vulnerable ecosystems to be affected by natural disturbances and human interference [1] [2] [3] [4]. Mangrove forests are unique ecosystems that provide important ecological services for coastal habitat and coastal protection [5] [6]. These ecosystems, however, are under high pressure due to over exploitation, and are declining at an alarming rate [2] [6]. Despite this rapid decline, and their importance, mangrove forest ecosystems have not received much publicity, particularly in regard to conservation and rehabilitation [6] [7]. Quantifying and monitoring the spatial and temporal dynamics of the mangrove ecosystem is essential for a better understanding of the many coastal land and sea processes. Traditionally, mapping a mangrove forest requires intensive field work, which is costly in time and money, as mangroves are inaccessible or difficult to field survey [6] [8]. Satellite remote sensing has a great potential for mapping and monitoring changes in mangrove forests, as the space based technology allows for collecting information from the landscape which is otherwise particularly difficult to access [9] [10].

[2] [11] have provided a detailed summary with an overview of remote-sensing research activities, including critical analysis that has been performed in the last few decades. Green et al. (1998) and Kuenzer et al. (2011) highlighted the importance of understanding the local environment when using remote sensing based mapping and monitoring. In recent years, several studies have been published, illustrating hyperspectral airborne and spaceborne data applications, including AISA, CASI, Hymap, AVIRIS, Dedalus, and EO-1 hyperian [6] [11] [12] [10]. High resolution imagery applications such as IKONOS, Quickbird, Rapid Eye and WorldView-3, have been very effective in discriminating mangrove forests from other forms of land use [13] [14] [15] [16]. However, limited spectral bands, complex data collection, and analysis methods, along with their high cost, are major limiting factors in using hyperspectral and high resolution data [2] [9] [17]. Few studies reported the use of RADAR data, with the inclusion of ALOS PALSAR, ERS-1/2 and Radarsat-1 SAR, as a tool in the mangrove classification framework, having found that classification and mapping accuracy requires improvement [2] [18] [19] [20]. In previous studies, optical remote sensing imagery, like the Landsat Multispectral Scanner (MSS), Landsat Thematic Mapper (TM), and Indian Remote Sensing satellites (IRS), SPOT XS, and SPOT-5, have been commonly used for mangrove forest mapping as the data is available via free access, or at a low cost [10] [21]. The recent developments in the series of 
Landsat satellites, such as the Operational Land Imager (OLI)-8 and Sentinel-2, have added a new dimension to long term data. The availability of multiple spectral band records over the long term, means the Landsat series can be used for accurate mapping and monitoring of mangrove forests [22]. Additionally, the application of the non-parametric or machine learning classifiers are very efficient for land use and land cover (LULC) mapping, even if still not abundant in mangrove mapping studies [23].

In recent years, there has been an increase in high-performance cloud computing platforms, such as the NASA Earth Exchange (NEX), Amazon Web Service (AWS) and Google Earth Engine (GEE). These high performance cloud computing platforms allow free access to the vast and fast growing earth observation data for global, as well as regional studies [24] [25]. For example, GEE provides preprocessed Landsat data (1982-present), along with the required disk space and advanced classification machine learning algorithms [25].

In Southeast Asia, large areas of the coastal zones have been occupied by mangrove forests [26]. According to the Asian Development Bank Regional Review on the Economics of Climate Change in Southeast Asia [27], the reduction in the size of mangroves resulted in coastal erosion in Thailand, and in neighboring countries. While the extent of these changes remains limited, means of sustainable management and future rehabilitation remains highly uncertain [2] [11] [28]. In recent decades, Thailand's mangrove forest area has substantially decreased as a result of human settlements, transport infrastructure, agriculture, and aquaculture [26] [29]. According to NESDB, while inconclusive in most regions, 30\% of mangrove forest was lost during 1961-1996 due to the conversion of mangrove forest to shrimp farms.

Given the above factors, the main objective of this study is to quantify the presence of mangrove forests in Thailand's Trat Province over the last 30 years (1987-2017) using Landsat imagery and GEE cloud computing, as well as developing an operational wall-to-wall change detection methodology based on long time series analysis.

\section{Study Area and Methodology}

\subsection{Study Area}

The study area is located in the Trat Province, eastern Thailand, on the border with Cambodia and along the Gulf of Thailand (Figure 1). It covers an area of approximately $240 \mathrm{~km}^{2}$ of witch $106 \mathrm{~km}^{2}$ of mangrove forest. Since ever, local communities have benefit from goods and services provided by the forest but in recent years, mangroves have been heavily exploited for timber extraction, charcoal production and shrimp farms. [30] reported that, after the 1980's, thanks to the effort of the Department of Marine and Coastal Resources, Thailand has reaerated this area. Villagers to this day, continue to use mangrove wood for various domestic purposes. 


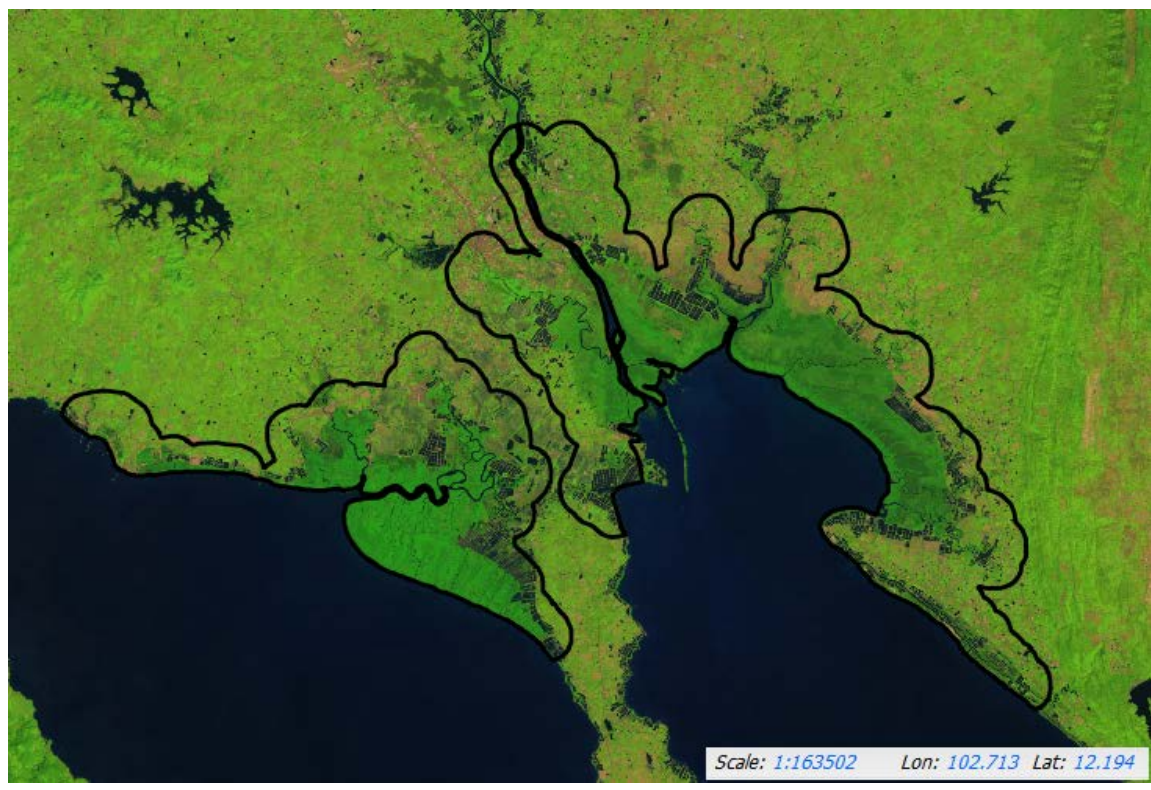

Figure 1. Location and extent of the study area in the Trat Province of Thailand including $850 \mathrm{mt}$ buffer around mangrove forest (source: Google Earth 2017).

\subsection{Landsat Imagery}

Data consists of Landsat TM, ETM+, and OLI Tier 1 top-of-atmosphere (TOA) reflectance as obtained from GEE image collections. The red, green, blue, NIR, SWIR-1, and SWIR-2 spectral bands of the TM-5, 7 ETM+, and OLI-8 platforms, were considered in the analysis. Jagged pixels at the edges of Landsat TM-5 images were removed using the $450 \mathrm{~m}$ inward buffer, which ensures the best available reflectance values for image analysis [31]. Annual composites were created by using the median reflectance values of the collection (all images for a target year e.g. 1987, from 01/01/1987 to 31/12/1987) [24], after been cleaned from cloudy or no-data pixels following the algorithm proposed by [32], and available in GEE. The algorithm is driven by predefined knowledge-based rules built upon the spectral signature collected on a global scale, and generates a thematic output including a cloud mask.

The TOA imagery was atmospherically corrected using a Dark Object Subtraction (DOS) method [33]. Using a forest normalization method, the median value of the mangrove forest pixels was used to apply a linear shift to each spectral band [34] [35]. Prior to classification, the Normalized difference vegetation index (NDVI) [11] [36], and Normalized difference infrared index (NDII) [37], has be computed to mask the composite from residual clouds or no data.

The Landsat imagery used in this study from 1987-2017 was from the Landsat TM-5 (1987-2001, and 2003-2011), Landsat ETM+7 (2002) and Landsat OLI-8 (2013-2017) sensors respectively. The year 2012 was excluded from the analysis due to missing data.

\subsection{Training and Validation Data}

One of the major issues of classifying historical images by using training and va- 
lidation samples, is often the lack of field data or so called ground-truth [38]. The design of a systematic training and validation dataset across a specified area is crucial for identifying major changes in mangrove forests over time. The design must be a good representation of major Land Use Land Cover (LULC) classes, with the dataset sufficiently large to provide reliable estimates [35]. The unsupervised classification was performed on the Landsat OLI-8 year $2017 \mathrm{im}$ ages to establish thematic categories of LULC. The most recent image was chosen for stratification to avoid the effect of the LULC change on training and testing design. Later the stratified random sampling approach was used to estimate the total number of samples per class [39] [40]. The stratification and selection of independent sample design focused on each five-year interval to ensure a stable change identification [39]. In total, 414 sample locations [Figure 2] were selected for LULC classification: class 1, active agriculture; class 2, bare land and urban areas (some agricultural land without vegetation was included here); class 3, mangrove forest; and class 4 , shrimp and fish farms. To establish each class, training samples were obtained: 150 for agriculture, 50 for bare land and urban areas, 164 for mangrove forest, and 50 for shrimp and fish farms. Among these sample locations, 109 were randomly selected to be set aside as validation samples. In March, 2015 and October 2016, a field mission was conducted in the study area to collect training and validation data for mangrove mapping. About 60 mangrove forest samples were collected during these missions, and were used along with a combination of Google Earth images, high-resolution satellite imagery, aerial photographs, and prior knowledge, for use as samples of the remaining classes. A distance of 500 meters separated each sample to avoid spatial autocorrelation, while training and validation pixels remained independent of each other. In the process of classification, the reference training and testing data were first developed for each year and then used in the classifier [41].

\subsection{Pixel Based Random Forest (RF) Classifier}

We performed a supervised pixel-based classification using a Random Forest (RF), a tree based classifier that includes K-decision trees [42] [43]). RF overcome the problem of overfitting by constructing an ensemble of decision trees [43] [44]. [44] reported that there are accurate and higher performance RF classifiers in land cover classification studies. The RF classifier was used to classify the extent of mangrove vegetation and other LULC in a study area, as shown in Figure 1. We trained the RF classifier (20 trees) in the GEE environment with 305 training samples to then classify the annual composite Landsat images into four LULCs: active agriculture (orchid plants, coconut grows, oil palm and rubber plantation), bare land/urban area/non-active agriculture plots, primary mangrove forest, and water bodies (fish and shrimp farms, and other water resources including water canals within mangrove forest). The categories were based on a detailed analysis of the study area, and reviewing previous studies and field surveys conducted for training and testing data. The RF classifier 


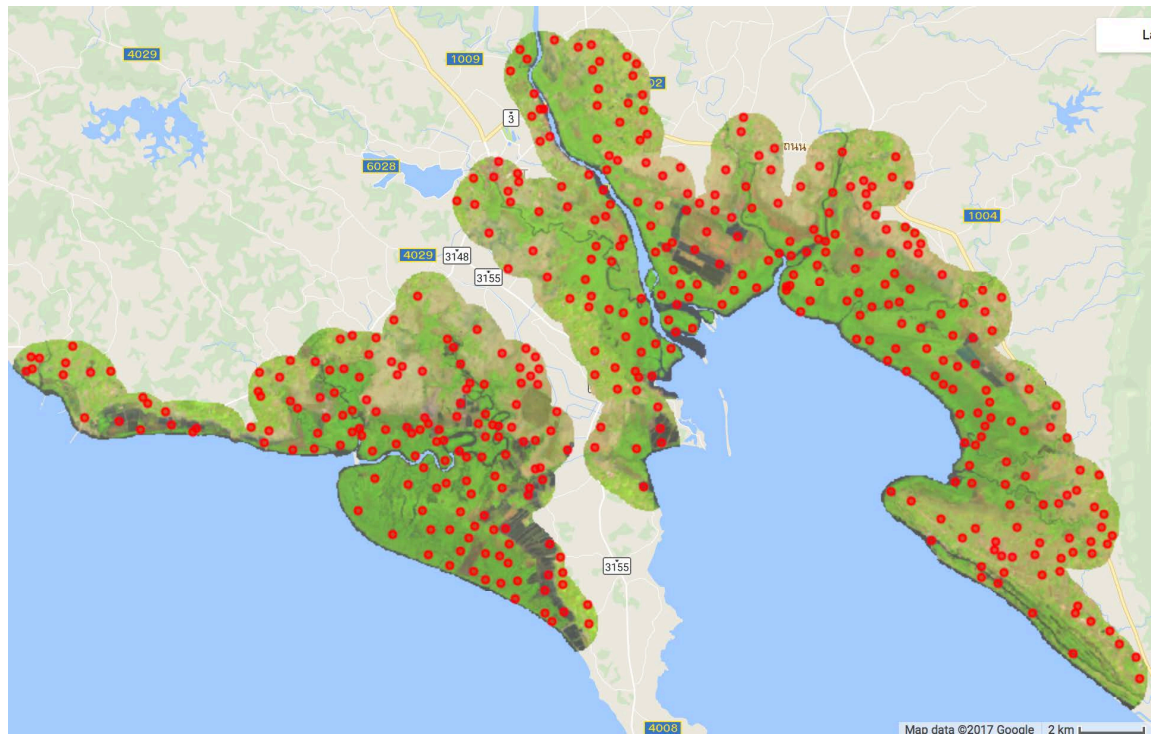

(a)

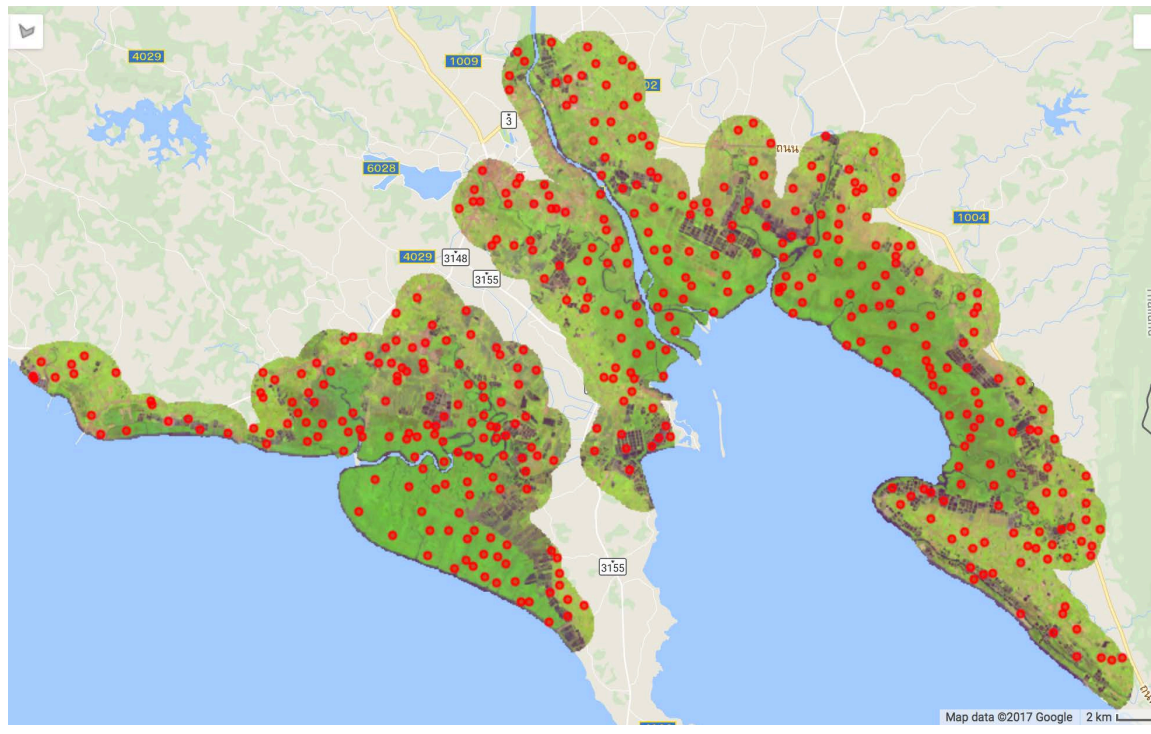

(b)

Figure 2. Locations of training and testing samples in the study area. A total of 414 points were created using the stratified random sampling approach, of which 109 were used as validation points (a) Training and testing samples for the year 1987; (b) Training and testing samples for the year 2017 (The figure contains back ground Google Earth engine map background and Landsat image for individual year).

was performed on red, green, blue, NIR, SWIR-1, and SWIR-2 spectral bands of each annual composite.

\subsection{Validation}

During the classification process, composite from different years are trained and validated individually. About $70 \%$ of the sample points are used to train the classifier, while the remaining $30 \%$ of samples were used to test the accuracy and validate the RF classifier (Figure 2). The RF classifier accuracy and Kappa statistics 
is assessed by an error matrix. The final maps were compared with high resolution aerial imagery available in Google Earth for visual refinement.

\subsection{Post Classification Change Detection}

Several methods such as an image overlay, change vector analysis, image rationing, and principal component analysis have been used in LULC mapping studies [44] [45]. In this study, the "From-to" change detection algorithm (Post-classification comparison), has been used to provide detailed information about the type of LULC change [46] [47]. The main advantage of post classification change detection is indicating the nature and magnitude of the LULC changes that had taken place over a time.

\section{Results}

\subsection{Cloud Free Annual Mosaic of Landsat Series}

Clouds and shadows represent one of the main sources of issue while working with optical remote sensed imagery such as Landsat, particularly when working in tropical regions. Figure 3(a) illustrates the influence of clouds, haze and missing pixels on Landsat series imagery, which could be the main limiting factor on the spatial and temporal consistency of long term mangrove ecosystem changes mapping and monitoring. The cloud cover, shadows, availability of haze and missing data, influence many data analysis processes including inaccurate atmospheric correction, biased vegetation indexes, mistakes in land cover classification and false detection of land use and land cover change [48]. The cloud free seamless mosaic of Landsat series imagery was created with a predefined knowledge-based rule built upon the spectral signature [32]. Annual composites were created by taking median reflectance values of the collection. Seamless and cloud free image mosaics can be important when mapping mangrove forests, because the cloud and seams can affect the visual interpretation of training sample collection, or leading to erroneous classifications [49]. Cloud free and seamless mosaic images would likely improve the results of the forest normalization method described in Section 2.2.

The comparable visual results presented in Figure 3(a) and Figure 3(b), were acquired by Landsat TM-5, ETM+ 7, and OLI-8. Their corresponding pseudo color composite (SWIR1, NIR, Red) before and after pre-processing for Landsat TM-5, ETM+ 7 OLI-8 are shown in Figure 3(a) and Figure 3(b). Several images in Figure 1(a) contains cloud, shadows, haze and missing data. The automatic rule-based algorithm was used to remove contamination in individual Landsat imagery. Figure 3(b) illustrates the cloud, haze and missing data free annual composite for the period of 1987-2017. In addition, the obtained composite revealed more vivid tone when compared with the original imagery. The selected contaminated pixels were tested using NDVI and NDII to mask the composite from residual clouds or no data. Only a selected annual composite image was classified, and stratified random samples generated. 


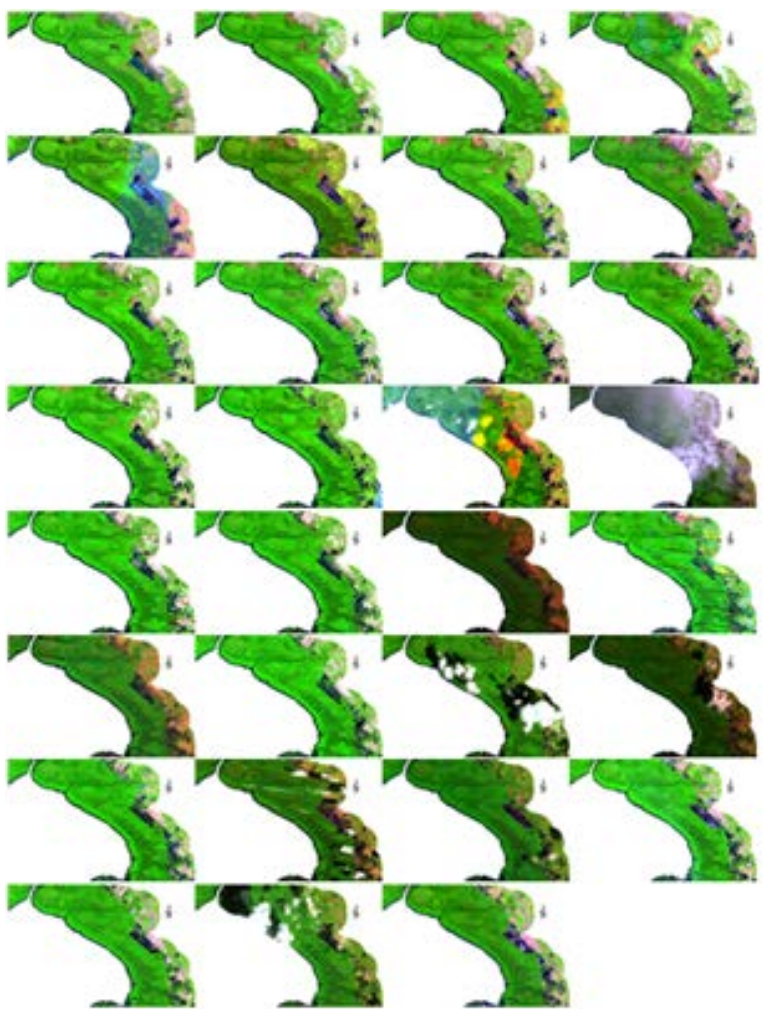

(a)

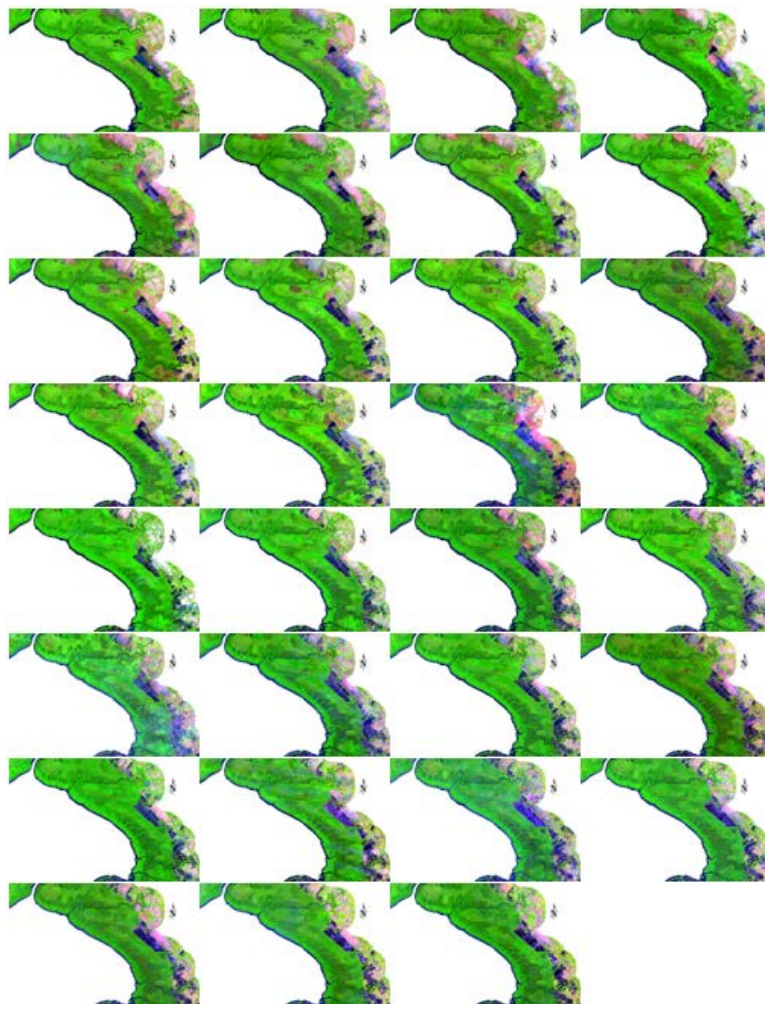

(b)

Figure 3. Pseudo color (SWIR1, NIR, Red) Landsat imagery from 1987 (upper left) to 2017 (bottom right) (a) best (less cloudy) available Landsat image for each year; (b) annual Landsat cloud free composites. 


\subsection{Magnitude of Mangrove and Its Surrounding Change}

In order to test the performance of consistent long term imagery from different Landsat sensors for mangrove forests and their surroundings, Landsat imagery was used representing two time periods (1987 and 2017). The stratified buffer was generated around the mangrove forest. A 850 meter buffer was generated to delineate the potential loss or gain of mangrove forest [Figure 1] within the surrounding landscape. The buffer was designed and based on the change in mangrove pixels within the study area using Normalized Differential Vegetation Index (NDVI), Normalized Difference Infrared Index (NDII), Digital Elevation Model(DEM), and Automatic Classification [10] [11] [32] [36] [50] [51]. A visual refinement has been carried out for year 1987 and 2017 (Landsat TM-5, $\mathrm{ETM}+7$, and OLI- 8 imagery respectively), to ensure the high quality of the mask over the time interval.

Independent training and validation data was used for the years 1987 and 2017. The LULC maps for the years 1987 and 2017 were based on Landsat TM-5 and OLI-8 satellite imagery that were prepared with four LULC types: class 1 , active agriculture, class 2, bare land and urban area (some agricultural land without vegetation was included here), class 3, mangrove forest and class 4 , shrimp and fish farms. Figure 4 shows the final classification of the RF classifier, which consists of classified maps of the study area, for the year 1987 and 2017.

Table 1 shows the results obtained from the classified map of 1987 and 2017. An overall accuracy of 0.87 and 0.96 , followed by a Kappa coefficient 0.80 and 0.94, were obtained. As a result, the performance of the RF classifier for the year 2017 produced a higher accuracy classification map with an overall accuracy of 0.96. On the other hand, the classification performance in 1987 was less than

Table 1. Error matrix and accuracy statistics for classification for the years 1987 and 2017 (class 1, active agriculture; class 2, bare land and urban area (some agricultural land without vegetation was included here); class 3 , mangrove forest; and class 4 , shrimp and fish farms).

\begin{tabular}{ccccc}
\hline LULU in 1987 & Class 1 & Class 2 & Class 3 & Class 4 \\
\hline Class 1 & 28 & 5 & 1 & 0 \\
Class 2 & 4 & 3 & 2 & 0 \\
Class 3 & 2 & 0 & 50 & 0 \\
Class 4 & 0 & 0 & 0 & 14 \\
& Overall accuracy $=0.87$, Kappa statistics $=0.80$ & \\
LULC in 2017 & Class 1 & Class 2 & Class 3 & Class 4 \\
Class 1 & 40 & 0 & 2 & 0 \\
Class 2 & 2 & 17 & 0 & 0 \\
Class 3 & 1 & 0 & 58 & 0 \\
Class 4 & 0 & 0 & 0 & 12 \\
& Overall accuracy $=0.96$, Kappa statistics & $=0.94$ & \\
\hline
\end{tabular}




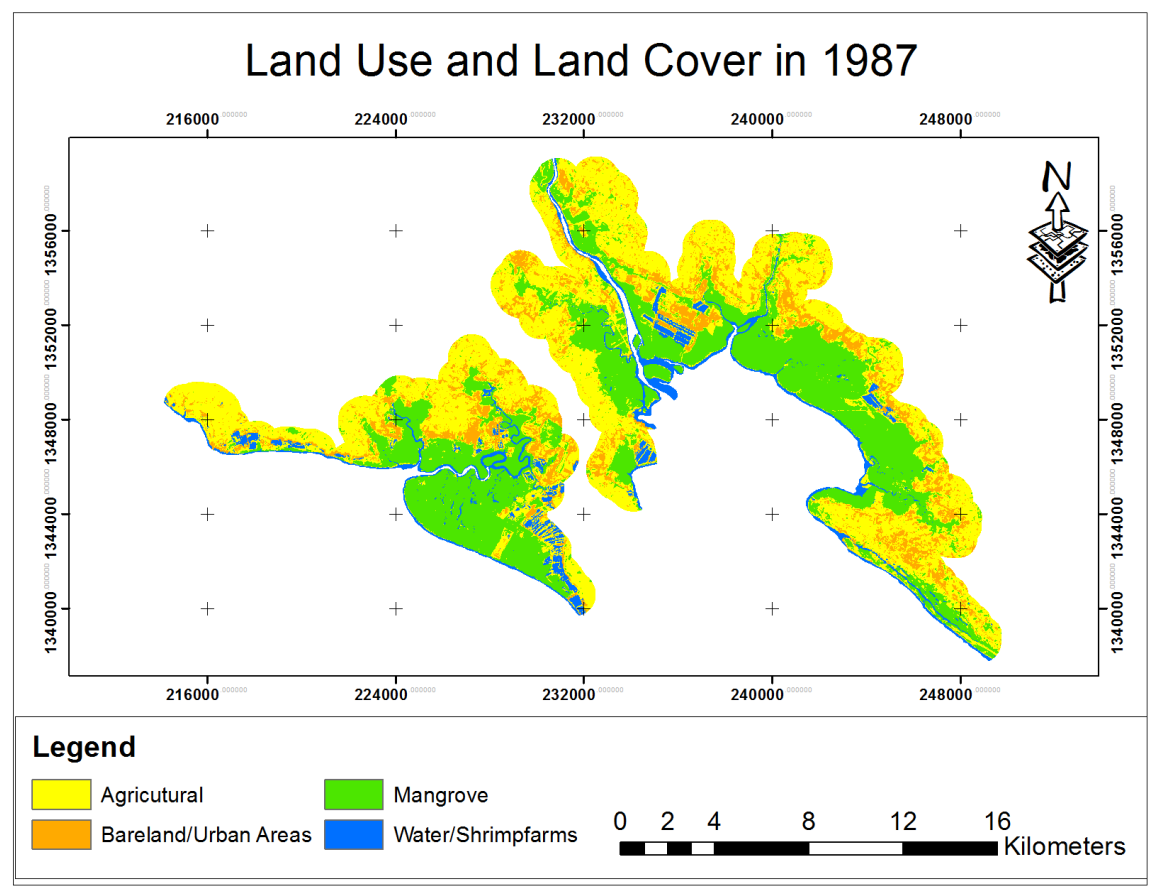

(a)

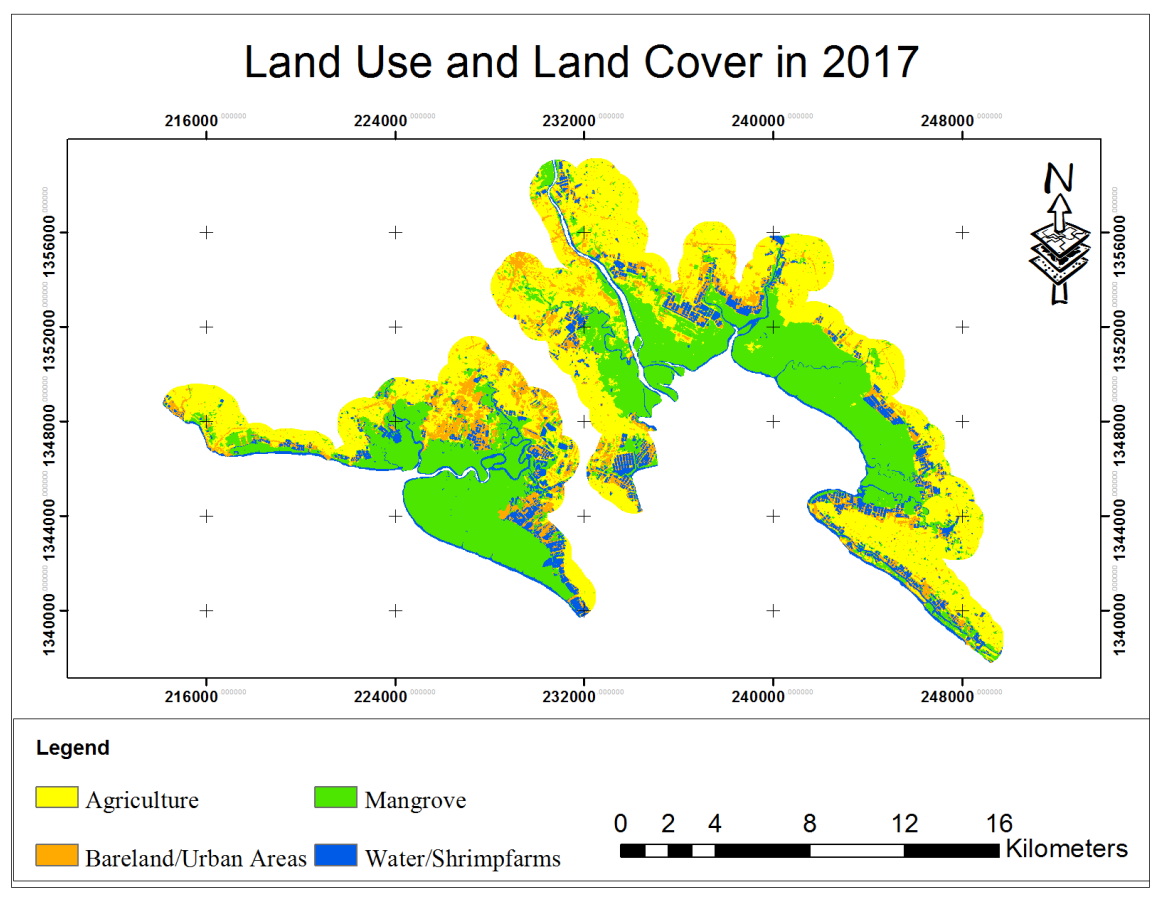

(b)

Figure 4. LULC map for the years (a) 1987 and (b) 2017.

that when compared with the year 2017. However, the classification confused agriculture (class 1), and bareland (class 2), for the year 1987, due to the similar spectral response and scarcity of ground truth data. Jia et al., 2014, also reported the high performance of Landsat OLI-8 when compared with that of Landsat TM-5 and ETM+ 7. 
Table 2 summarizes the results of the LULC change in the study area of each LULC class. The agriculture and mangrove forest was the main LULC in 1987 with $49.18 \%$ and $34.20 \%$, followed by bareland/urban areas and water bodies/shrimp farms with $9.80 \%$ and $6.82 \%$ respectively. Agricultural area decreased from $49.18 \%\left(111.36 \mathrm{~km}^{2}\right)$ in 1987 to $41.25 \%\left(93.40 \mathrm{~km}^{2}\right)$ in 2017 , while, mangrove forest area increased from $34.20 \%\left(77.43 \mathrm{~km}^{2}\right)$ in 1987 to $36.17 \%$ $\left(81.90 \mathrm{~km}^{2}\right)$ in 2017 . Additionally, some of the disturbed mangrove forest area has shown significant recovery (Figures 5(a)-(d)). The bareland/urban areas increased from $9.80 \%\left(22.17 \mathrm{~km}^{2}\right)$ in 1987 to $11.08 \%\left(25.10 \mathrm{~km}^{2}\right)$ in 2017. Shrimp/fish farms progressively increased from $6.82 \%\left(15.16 \mathrm{~km}^{2}\right)$ in 1987 to $11.49 \%\left(26.02 \mathrm{~km}^{2}\right)$.

The decline in active agriculture was observed to be $7.93 \%$ between 1987 and 2017. Bareland/urban areas and shrimp/fish farms did experience an expansion during the period of 1987 to 2017 . Another increased rate of change was observed in the mangrove forest.

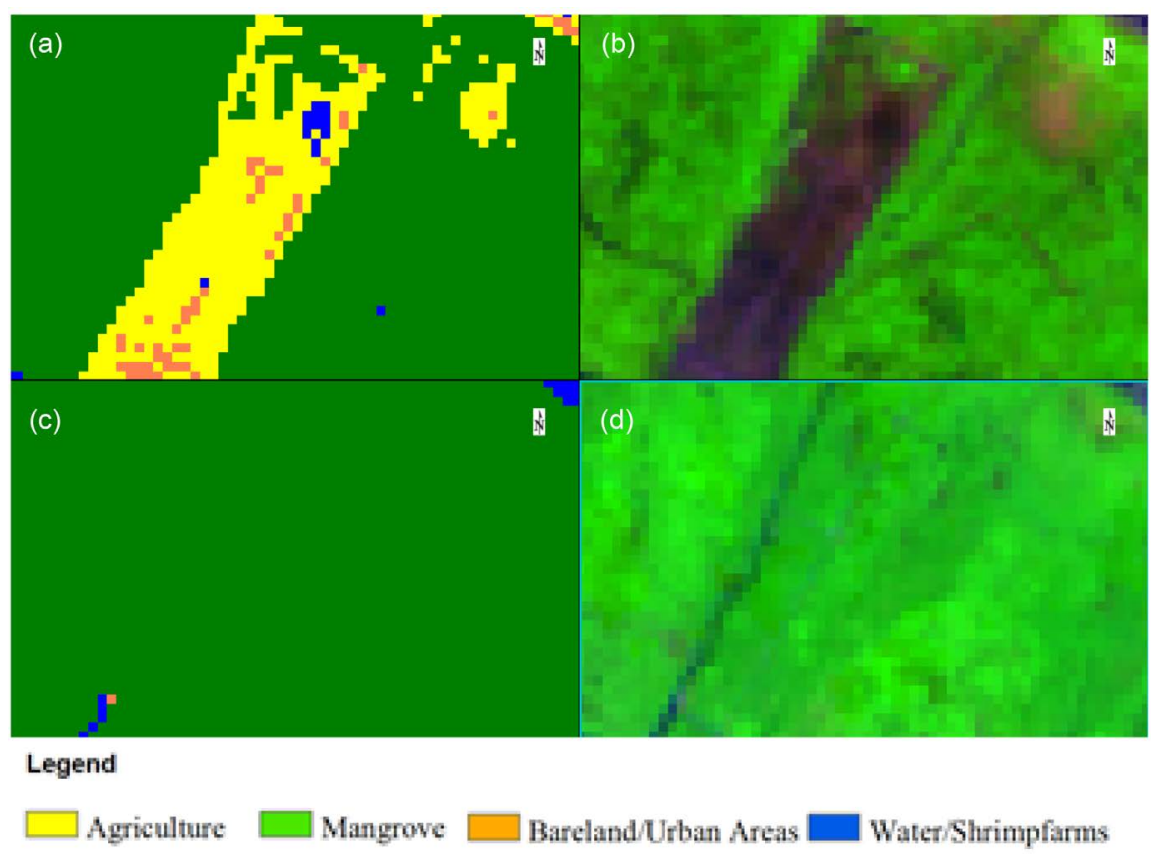

Figure 5. (a) classification of a distrubed patch; (b) Landsat TM-5 (Swir1, Nir, Red); c) classification of a recovered patch; (d) Landsat OLI-8 (Swir1, Nir, Red).

Table 2. Change in LULC area and percentage in study area.

\begin{tabular}{cccccc}
\hline \multirow{2}{*}{ LULC } & \multicolumn{2}{c}{1987} & \multicolumn{2}{c}{2017} & Change (1987-2017) \\
\cline { 2 - 5 } & $\mathrm{km}^{2}$ & $\%$ & $\mathrm{~km}^{2}$ & $\%$ & $\%$ \\
\hline Class 1 & 111.36 & 49.18 & 93.40 & 41.25 & 7.93 \\
Class 2 & 22.17 & 9.80 & 25.10 & 11.08 & -1.28 \\
Class 3 & 77.43 & 34.20 & 81.90 & 36.17 & -1.97 \\
Class 4 & 15.46 & 6.82 & 26.02 & 11.49 & -4.67 \\
Total area & 226.42 & 100 & 226.42 & 100 & \\
\hline
\end{tabular}




\subsection{LULC Change Transition from 1987 to 2017}

The transition matrix was used to analyse the rates of LULC conversion from one LULC to another for the years 1987 and 2017. The corresponding probablities of change are shown in Table 3 . There was a major conversion of agriculture to bareland $\left(15.15 \mathrm{~km}^{2}\right)$ and from agricuture to mangrove forest $\left(8.40 \mathrm{~km}^{2}\right)$ during this period. At the same time, mangrove forest changed to shrimp/fish farm $\left(4.72 \mathrm{~km}^{2}\right)$, and bareland was converted to shrimp/fish farms.

Table 3. Land Use Land Cover (LULC) change matrix between 1987 and 2017.

\begin{tabular}{cccccc}
\hline LULC type & Class 1 & Class 2 & Class 3 & Class 4 & Total in 1987 \\
\hline Class 1 & $\mathbf{6 8 . 0 8}$ & 13.57 & 11.59 & 7.39 & 100.64 \\
Class 2 & 15.15 & 6.94 & 3.32 & 3.45 & 28.88 \\
Class 3 & 8.40 & 3.91 & 63.97 & 5.24 & 81.53 \\
Class 4 & 0.61 & 1.59 & 4.72 & $\mathbf{8 . 5 3}$ & 15.46 \\
Total in 2017 & 92.25 & 26.02 & 83.61 & 24.62 & 226.42 \\
\hline
\end{tabular}

Note: The bold numbers indicate that there is no change in LULC over the study period.

\section{Discussion}

\subsection{Overcoming the Limitations with Landsat Series Imagery for Mangrove Forest Mapping}

Landsat series imagery are very helpful for detecting long term changes in mangrove ecosystems. [52] have highlighted several limitations of existing Landsat satellites, challenging the wall-to-wall mapping of wetland ecosystems, such as Landsat-5, which no longer has global coverage; and a mechanical fault in the Scan-Line Corrector (SLC-Off) on the Landsat-7 satellite, with a $22 \%-25 \%$ data loss with each image. Other limitations also factor into the mix, including the presence of atmospheric contamination such as cloud, haze and missing data in Landsat imagery, which are major limitations in long term mapping and monitoring of costal ecosystems [53] [54].

In this study, knowledge-based predefined rules were used to remove the contaminated pixels from all the available imagery and used the annual median reflectance value of the collection for a consistent annual composite. Consistent imagery over a long time series will likely support detection of other spectrally non-stubble changes such as forest clearing, regrowth and undisturbed ecosystems [55]. Consistent error free and seamless composite images make it possible to achieve fast and accurate classification, making it easier to detect LULC change (e.g. in this study, the machine learning Random Forest classfier was tested).

The annual composites from 1987-2017 are virtually seamless regardless of the presence of atmospheric contamination and sensor artifacts such as the SLC-Off (Landsat-7) and missing pixel data. Benefits introduced by implementing this methodological framework in GEE are threefold: 
- easy and user friendly programming environment

- virtually unlimited processing power with high computationally efficiency

- raw satellite data are already available on GEE servers hence no need to retrieve and download huge amount of data (less local resources)

\subsection{Change in LULC}

The results show that a significant change occurred in land cover, particularly in mangrove forests, in the surrounding areas of Trat, between 1987 and 2017. It appears that agriculture, bareland and shrimp farmshad undergone major changes. However, there is very little research has been conducted study of these changes. The mangrove forests made a significant recovery over time. This trend is indicative of the local community's awareness for mangrove forest conservation and in the detrimental effect that shrimp farming can have on mangrove forest conservation. [56] reported on the expansion of shrimp farming (1972-1995), and low-salinity shrimp farming (1996-2002). He also reported that recently, (2003-2004), the Thai government's policies restricted the expansion of low-salinity shrimp farming within the freshwater regions of the country. The result of this study suggests that the rapid changes in agriculture, bareland, and shrimp farms, and their interconversion, are a major driver of the change.

\section{Conclusions}

This paper presents a new strategy in attempting to achieve error free 30 year annual composites of Landsat satellites imagery for mapping mangroves and their surrounding LULC changes on the GEE cloud computing platform. This strategy uses pre-defined knowledge-based rules to remove contaminated pixels from all available imagery and uses annual median reflectance values in the collection. A fast, accurate and stable detection of change in agriculture, bare lands, mangrove forests, and shrimp/fish farms generated from consistent seamless mosaic and the RF classifier, demonstrates these results. The study area experienced drastic interchange between agriculture, bare land and shrimp/fish farms, while mangrove forests had made a recovery over a period of time.

The study contributes to the application of cloud computing GEE and its potential for costal ecosystem mapping and monitoring. The provided reliable and consistent long term satellite data and high performance classification approach could be beneficial for finding changes in mangrove ecosystems and their surroundings to fill the gaps necessary for forest management, conservation, as well as in understanding their carbon sequestration potential.

\section{Acknowledgements}

This research was initially funded by Asahi Glass Foundation Japan. This research was carried out in collaboration with Royal Forest Department of Thailand. 


\section{References}

[1] Kanniah, K.D., Sheikhi, A., Cracknell, A.P., Goh, H.C., Tan, K.P., Ho, C.S. and Rasli, F.N. (2015) Satellite Images for Monitoring Mangrove Cover Changes in a Fast Growing Economic Region in Southern Peninsular Malaysia. Remote Sensing, 7, 14360-14385. https://doi.org/10.3390/rs71114360

[2] Kuenzer, C., Bluemel, A., Gebhardt, S., Quoc, T.V. and Dech, S. (2011) Remote Sensing of Mangrove Ecosystems: A Review. Remote Sensing, 3, 878-928.

https://doi.org/10.3390/rs3050878

[3] Gilman, E.L., Ellison, J., Duke, N.C. and Field, C. (2008) Threats to Mangroves from Climate Change and Adaptation Options: A Review. Aquatic Botany, 89, 237-250. https://doi.org/10.1016/j.aquabot.2007.12.009

[4] Jhonnerie, R., Siregar, V.P., Nababan, B., Prasetyo, L.B. and Wouthuyzen, S. (2015) Random Forest Classification for Mangrove Land Cover Mapping Using Landsat 5 TM and Alos Palsar Imageries. Procedia Environmental Sciences, 24, 215-221. https://doi.org/10.1016/j.proenv.2015.03.028

[5] Son, N.T., Chen, C.F., Chang, N.B., Chen, C.R., Chang, L.Y. and Thanh, B.X. (2015) Mangrove Mapping And Change Detection in Ca Mau Peninsula, Vietnam, Using Landsat Data and Object-Based Image Analysis. IEEE Journal of Selected Topics in Applied Earth Observations and Remote Sensing, 8, 503-510. https://doi.org/10.1109/JSTARS.2014.2360691

[6] Giri, C., Pengra, B., Zhu, Z., Singh, A. and Tieszen, L.L. (2007) Monitoring Mangrove Forest Dynamics of the Sundarbans in Bangladesh and India Using Multi-Temporal Satellite Data from 1973 to 2000. Estuarine. Coastal and Shelf Science, 73, 91-100. https://doi.org/10.1016/j.ecss.2006.12.019

[7] Valiela, I., Bowen, J.L. and York, J.K. (2001) Mangrove Forests: One of the World's Threatened Major Tropical Environments. BioScience, 51, 807. https://doi.org/10.1641/0006-3568(2001)051[0807:MFOOTW]2.0.CO;2

[8] Zhang, C., Kovacs, J.M., Liu, Y., Flores-Verdugo, F. and Flores-de-Santiago, F. (2014) Separating Mangrove Species and Conditions Using Laboratory Hyperspectral Data: A Case Study of a Degraded Mangrove Forest of the Mexican Pacific. Remote Sensing, 6, 11673-11688. https://doi.org/10.3390/rs61211673

[9] Son, N.T., Chen, C.F., Chang, N.B., Chen, C.R., Chang, L.Y. and Thanh, B.X. (2015) Mangrove Mapping and Change Detection in Ca Mau Peninsula, Vietnam, Using Landsat Data and Object-Based Image Analysis. IEEE Journal of Selected Topics in Applied Earth Observations and Remote Sensing, 8, 503-510. https://doi.org/10.1109/JSTARS.2014.2360691

[10] Jia, M., Zhang, Y., Wang, Z., Song, K. and Ren, C. (2014) Mapping the Distribution of Mangrove Species in the Core Zone of Mai Po Marshes Nature Reserve, Hong Kong, Using Hyperspectral Data and High-Resolution Data. International Journal of Applied Earth Observation and Geoinformation, 33, 226-231. https://doi.org/10.1016/j.jag.2014.06.006

[11] Green, E.P., Clark, C.D., Mumby, P.J., Edwards, A.J. and Ellis, A.C. (1998) Remote Sensing Techniques for Mangrove Mapping. International Journal of Remote Sensing, 19, 935-956. https://doi.org/10.1080/014311698215801

[12] Yang, C., Everitt, J.H., Fletcher, R.S., Jensen, R.R. and Mausel, P.W. (2009) Evaluating AISA+ Hyperspectral Imagery for Mapping Black Mangrove along the South Texas Gulf Coast. Photogramm. Eng. Remote Sensing, 75, 425-435. https://doi.org/10.14358/PERS.75.4.425

[13] Wang, L., Sousa, W.P. and Gong, P. (2004) Integration of Object-Based and Pix- 
el-Based Classification for Mapping Mangroves with IKONOS Imagery. International Journal of Remote Sensing, 25, 5655-5668. https://doi.org/10.1080/014311602331291215

[14] Wang, L., Sousa, W.P., Gong, P. and Biging, G.S. (2004) Comparison of IKONOS and QuickBird Images for Mapping Mangrove Species on the Caribbean Coast of Panama. Remote Sensing of Environment, 91, 432-440. https://doi.org/10.1016/j.rse.2004.04.005

[15] Myint, S.W., Giri, C.P., Wang, L., Zhu, Z. and Gillette, S.C. (2008) Identifying Mangrove Species and Their Surrounding Land Use and Land Cover Classes Using an Object-Oriented Approach with a Lacunarity Spatial Measure. GIScience \& Remote Sensing, 45, 188-208. https://doi.org/10.2747/1548-1603.45.2.188

[16] Huang, X., Zhang, L. and Wang, L. (2009) Evaluation of Morphological Texture Features for Mangrove Forest Mapping and Species Discrimination Using Multispectral IKONOS Imagery. IEEE Geoscience and Remote Sensing Letters, 6, 393-397. https://doi.org/10.1109/LGRS.2009.2014398

[17] Aslan, A., Rahman, A.F., Warren, M.W. and Robeson, S.M. (2016) Mapping Spatial Distribution and Biomass of Coastal Wetland Vegetation in Indonesian Papua by Combining Active and Passive Remotely Sensed Data. Remote Sensing of Environment, 183, 65-81. https://doi.org/10.1016/j.rse.2016.04.026

[18] Rao, B.R., Dwivedi, R.S., Kushwaha, S.P., Bhattacharya, S.N., Anand, J.B. and Dasgupta, S. (1999) Monitoring the Spatial Extent of Coastal Wetland Using ERS-1 SAR Data. Int. J. Remote Sens., 20, 2509-2517. https://doi.org/10.1080/014311699211903

[19] Lucas, R.M., Carreiras, J., Proisy, C. and Bunting, P. (2008) ALOS PALSAR Applications in the Tropics and Subtropics: Characterisation; Mapping and Detecting Change in Forests and Coastal Wetlands. Proceedings of Second ALOS PI Symposium, Rhodes, Greece, 3-7 November 2008.

[20] Kovacs, J.M., Vandenberg, C.V. and Flores-Verdugo, F. (2006) Assessing Fine Beam RADARSAT-1 Backscatter from a White Mangrove (Laguncularia racemosa (Gaertner)) Canopy. Wetlands Ecol. Manage., 14, 401-408. https://doi.org/10.1007/s11273-005-6237-x

[21] Liu, Z., Li, J.B., Lim, B., Seng, C., Inbaraj, S. and Sun, Z. (2008) Local Spatial Statistics for Remotely Sensed Image Classification. The International Archives of the Photogrammetry, Remote Sensing and Spatial Information Sciences, XXXVII(B7).

[22] Shapiro, A.C., Trettin, C.C., Küchly, H. and Alavinapanah, S. (2015) The Mangroves of the Zambezi Delta. Increase in Extent Observed via Satellite from 1994 to 2013, 16504-16518.

[23] Jhonnerie, R., Siregar, V.P., Nababan, B., Prasetyo, L.B. and Wouthuyzen, S. (2015) Random Forest Classification for Mangrove Land Cover Mapping Using Landsat 5 TM and Alos Palsar Imageries. Procedia Environmental Sciences, 24, 215-221. https://doi.org/10.1016/j.proenv.2015.03.028

[24] Midekisa, A., Holl, F., Savory, D.J., Andrade-pAcheco, R., Gething, W., Bennett, A. and Sturrock, H.J.W. (2017) Mapping Land Cover Change over Continental Africa Using Landsat and Google Earth Engine Cloud Computing, (30 m), 1-15.

[25] Giri, C., Long, J., Abbas, S., Murali, R.M., Qamer, F.M., Pengra, B. and Thau, D. (2015) Distribution and Dynamics of Mangrove Forests of South Asia. Journal of Environmental Management, 148, 101-111. https://doi.org/10.1016/j.jenvman.2014.01.020

[26] Thampanya, U., Vermaat, J.E., Sinsakul, S. and Panapitukkul, N. (2006) Coastal 
Erosion and Mangrove Progradation of Southern Thailand. Estuarine, Coastal and Shelf Science, 68, 75-85. https://doi.org/10.1016/j.ecss.2006.01.011

[27] Asian Development Bank. (2009) The Economics of Climate Change in Southeast Asia: A Regional Review. Asian Development Bank (ADB).

[28] Vo, Q.T., Kuenzer, C., Vo, Q.M., Moder, F. and Oppelt, N. (2012) Review of Valuation Methods for Mangrove Ecosystem Services. Ecological Indicators, 23, 431-446. https://doi.org/10.1016/j.ecolind.2012.04.022

[29] National Economic and Social Development Board (NESDB) (2000) Mangrove Resources Management Plan for Sustainable Development, NESDB Paper, Bangkok, Thailand (Thai Version).

[30] Chalermchatwilai, B., Poungparn, S. and Patanaponpaiboon, P. (2011) Distribution of Fine-Root Necromass in a Secondary Mangrove Forest in Trat Province, Eastern Thailand. ScienceAsia, 37, 1-5. https://doi.org/10.2306/scienceasia1513-1874.2011.37.001

[31] Robinson, N.P., Allred, B.W., Jones, M. O., Moreno, A., Kimball, J.S., Naugle, D.E. and Richardson, A.D. (2017) A Dynamic Landsat Derived Normalized Difference Vegetation Index (NDVI) Product for the Conterminous United States. Remote Sensing, 9, 1-14. https://doi.org/10.3390/rs9080863

[32] Simonetti, D., Simonetti, E., Szantoi, A., Lupi, A. and Eva, H.D. (2015) First Results from the Phenology-Based Synthesis Classifier Using Landsat 8 Imagery. IEEE Geoscience and Remote Sensing Letters. 2, 1496-1500. https://doi.org/10.1109/LGRS.2015.2409982

[33] Bruce, C.M. and Hilbert, D.W. (2004) Pre-processing Methodology for Application to Landsat TM/ETM+ Imagery of the Wet Tropics. Cooperative Research Centre for Tropical Rainforest Ecology and Management. Rainforest CRC, Cairns, $44 \mathrm{p}$.

[34] Bodart, C., Eva, H., Beuchle, R., Rasi, R., Simonetti, D., Stibig, H.J. and Achard, F. (2011) Pre-Processing of a Sample of Multi-Scene and Multi-Date Landsat Imagery Used to Monitor Forest Cover Changes over the Tropics. ISPRS Journal of Photogrammetry and Remote Sensing, 66, 555-563. https://doi.org/10.1016/j.isprsjprs.2011.03.003

[35] Pimple, U., Sitthi, A., Simonetti, D., Pungkul, S., Leadprathom, K. and Chidthaisong, A. (2017) Topographic Correction of Landsat TM-5 and Landsat OLI-8 Imagery to Improve the Performance of Forest Classification in the Mountainous Terrain of Northeast Thailand. Sustainability, 9, 258. https://doi.org/10.3390/su9020258

[36] Higginbottom, T.P. and Symeonakis, E. (2014) Assessing Land Degradation and Desertification Using Vegetation Index Data: Current Frameworks and Future Directions. Remote Sensing, 6, 9552-9575. https://doi.org/10.3390/rs6109552

[37] Jackson, T.J., Chen, D., Cosh, M., Li, F., Anderson, M., Walthall, C. and Hunt, E.R. (2004) Vegetation Water Content Mapping Using Landsat Data Derived Normalized Difference Water Index for Corn and Soybeans. Remote Sensing of Environment, 92, 475-482. https://doi.org/10.1016/j.rse.2003.10.021

[38] Gomariz-Castillo, F., Alonso-Sarrí a, F., Montá vez, J.P. and Lorente-Plazas, R. (2017) An Open-Source Web Mapping Tool to Estimate Wind Energy in the Iberian Peninsula. Journal of Spatial Science.

[39] Olofsson, P., Foody, G.M., Herold, M., Stehman, S.V., Woodcock, C.E. and Wulder, M.A. (2014) Good Practices for Estimating Area and Assessing Accuracy of Land Change. Remote Sensing of Environment, 148, 42-57.

https://doi.org/10.1016/j.rse.2014.02.015 
[40] FAO (2016) Map Accuracy Assessment and Area Estimation Map Accuracy Assessment and Area Estimation: A Practical Guide. FAO, Rome.

[41] Peiman, R. (2011) Pre-classification and Post-Classification Change-Detection Techniques to Monitor Land-Cover and Land-Use Change Using Multi-Temporal Landsat Imagery: A Case Study on Pisa Province in Italy. International Journal of Remote Sensing, 32, 4365-4381. https://doi.org/10.1080/01431161.2010.486806

[42] Goldblatt, R., You, W., Hanson, G. and Khandelwal, A.K. (2016) Remote Sensing Detecting the Boundaries of Urban Areas in India: A Dataset for Pixel-Based Image Classification in Google Earth Engine, 1-28.

[43] Shelestov, A., Lavreniuk, M., Kussul, N., Novikov, A. and Skakun, S. (2017) Exploring Google Earth Engine Platform for Big Data Processing: Classification of Multi-Temporal Satellite Imagery for Crop Mapping. Frontiers in Earth Science, 5, 1-10. https://doi.org/10.3389/feart.2017.00017

[44] Pelletier, C., Valero, S., Inglada, J., Champion, N. and Dedieu, G. (2016) Assessing the Robustness of Random Forests to Map Land Cover with High Resolution Satellite Image Time Series Over Large Areas. Remote Sens. Environ, 187, 156-168. https://doi.org/10.1016/j.rse.2016.10.010

[45] Forkuo, E.K. and Frimpong, A. (2012) Analysis of Forest Cover Change Detection, International Journal of Remote Sensing Applications, 2, 82-92.

[46] Singh, A. (1989) Digital Change Detection Techniques Using Remotely-Sensed Data. Int J Remote Sens, 10, 989-1003. https://doi.org/10.1080/01431168908903939

[47] Foody, G.M. (2002) Status of Land Cover Classification Accuracy Assessment. Remote Sensing of Environment, 80, 185-201. https://doi.org/10.1016/S0034-4257(01)00295-4

[48] Zhu, Z. and Woodcock, C.E. (2012) Object-Based Cloud and Cloud Shadow Detection in Landsat Imagery. Remote Sensing of Environment, 118, 83-94 https://doi.org/10.1016/j.rse.2011.10.028

[49] Helmer, E.H., Ruzycki, T.S., Wunderle Jr, J.M., Vogesser, S., Ruefenacht, B., Kwit, C., Brabdeis, T.J. and Ewert, D.N. (2010) Mapping Tropical Dry Forest Height, Foliage Height Profiles and Disturbance Type and Age with Time Series of Cloud-Cleared Landsat and ALI Image Mosaic to Characterize Avian Habitat. Remote sensing of Environment, 144, 2457-2473.

https://doi.org/10.1016/j.rse.2010.05.021

[50] Yilmaz, M.T., Hunt, E.R., Goins, L.D., Ustin, S.L., Vanderbilt, V.C. and Jackson, T.J. (2008) Vegetation Water Content during SMEX04 from Ground Data and Landsat 5 Thematic Mapper Imagery. Remote Sensing of Environment, 112, 350-362. https://doi.org/10.1016/j.rse.2007.03.029

[51] Alsaaideh, B., Al-Hanbali, A., Tateishi, R., Kobayashi, T. and Hoan, N.T. (2013) Mangrove Forests Mapping in the Southern Part of Japan Using Landsat ETM+ with DEM. Journal of Geographic Information System, 5, 369-377. https://doi.org/10.4236/jgis.2013.54035

[52] Wijedasa, L.S., Sloan, S., Michelakis, D.G. and Clements, G.R. (2012) Overcoming Limitations with Landsat Imagery for Mapping of Peat Swamp Forests in Sundaland. Remote Sensing, 4, 2595-2618. https://doi.org/10.3390/rs4092595

[53] Mwita, E., Menz, G., Misana, S. and Nienkemper, P. (2012) Detection of Small Wetlands with Multi Sensor Data in East Africa. Advances in Remote Sensing, 1, 64-73. https://doi.org/10.4236/ars.2012.13007

[54] Cihlar, J. (2000) Land Cover Mapping of Large Areas from Satellites: Status and Research. International Journal of Remote Sensing, 21, 1093-1114. 
https://doi.org/10.1080/014311600210092

[55] Helmer, E.H. and Ruefenacht, B. (2005) Cloud-Free Satellite Image Mosaics with Regression Trees and Histogram Matching. Photogrammetric Engineering and Remote Sensing, 71, 1079-1089. https://doi.org/10.14358/PERS.71.9.1079

[56] Szuster, B.W. (2006) A Review of Shrimp Farming in Central Thailand and its Environmental Implications, in Shrimp Culture: Economics, Market, and Trade. Leung, P. and Engle, C., Eds. Blackwell Publishing, Ames, Iowa.

https://doi.org/10.1002/9780470277850.ch11 